\title{
Erratum to: Aggregation of public choice in Russia: national projects' potential
}

Yan Vaslavskiy $^{1}$

${ }^{1}$ Moscow State Institute for Foreign Relations (MGIMO University) 119454, Moskva, Russian Federation

Original article:

E3S Web Conf.

Volume 159,2020

The $1^{\text {st }}$ International Conference on Business Technology for a Sustainable Environmental System (BTSES-2020)

https://doi.org/10.1051/e3sconf/202015905007

The name and surname of the author of this article should be replaced as follows:

Yan Vaslavskiy

The name of the institution should be replaced as follows:

Moscow State Institute of International Relations (MGIMO University) 119454, Moscow, Russian Federation 